\title{
Proximity ligation in situ assay for monitoring the global DNA methylation in cells
}

\author{
Eric Hervouet ${ }^{1,2}$, Philippe Hulin ${ }^{2,3}$, François M Vallette ${ }^{1,2}$ and Pierre-François Cartron ${ }^{1,2^{*}}$
}

\begin{abstract}
Background: DNA methylation has a central role in the epigenetic control of mammalian gene expression, and is required for $\mathrm{X}$ inactivation, genomics imprinting and silencing of retrotransposons and repetitive sequences. Thus, several technologies have been developed to measure the degree of DNA methylation.

Results: We here present the development of the detection of protein-protein interactions via the adaptation of the proximity ligation in situ technology to evaluate the DNA methylation status in cells since the quantification of Dnmt1/PCNA interaction in cells reflects the degree of DNA methylation.

Conclusion: This method being directly realizable on cells, it appears that it could suggest a wide range of applications in basic research and drug development. More particularly, this method is specially adapted for the investigations realized from a weak quantity of biologic materiel such as stem cells or primary cultured tumor cells for examples.
\end{abstract}

Keywords: Global DNA methylation method, Dnmt1/PCNA, proximity ligation in situ technology

\section{Background}

DNA methylation has a central role in the epigenetic control of mammalian gene expression, and is required for $\mathrm{X}$ inactivation, genomics imprinting and silencing of retrotransposons and repetitive sequences $[1,2]$. The loss or the decrease of the 5 -methylcytosine number on DNA, i.e. the DNA hypomethylation process, is ones of the earlier hallmarks described in neoplasia [3]. Moreover, several paper reports that the DNA hypomethylation is an oncogenic event leading the chromosomal instability and the oncogenes expression $[4,5]$. Literature also mentioned that the degree of DNA hypomethylation has been also associated with the tumor progression and with the prognosis of survival of patients suffering of tumors [6]. Conjugated with the fact that the DNA methylation abnormalities are potentially reversible, all these points encouraged the development of pharmacologic inhibitors of DNA methylation and their use in anti-tumor therapies. Thus, the quantification of degree of DNA methylation in cells appears as a

\footnotetext{
* Correspondence: pierre-francois.cartron@univ-nantes.fr

${ }^{1}$ Centre de Recherche en Cancérologie Nantes-Angers, INSERM, U892, Equipe Apoptose et Progression Tumorale, Equipe labellisée Lique Nationale Contre le Cancer. 8 quai moncousu, BP7021, 44007 Nantes, France

Full list of author information is available at the end of the article
}

crucial point for its use in diagnosis, prognosis and the evaluation of the response to treatments including DNA methylation modulators.

Several technologies have been developed to measure the degree of DNA methylation [7]. A first group of technologies is focused around the use of methodologies that can quantify the 5-methyl cytosines using reversedphase high performance liquid chromatography (RPHPLC), two dimensional thin layer chromatography (2D-TLC), high performance liquid chromatographymass spectrometry (HPLC-MS), high performance capillary electrophoresis (HPCE) and liquid chromatographyelectrospray ionization-tandem mass spectrometry (LC-ESI-MS/MS) [8,9]. A second group of technologies has been developed to quantify the global 5-methylcytosine via the radiolabelling of $\mathrm{CpG}$ sites, ELISA method, pyrosequencing, use of methyl-sensitive enzymes in COBRA method for example [10,11]. Literature also mentions a third group of technologies in which the degree of DNA methylation is analyzed by measuring the activity of enzymes catalyzing the DNA methylation: the DNA methyltransferases [12]. However, all these methods require multiple steps of works and a sufficient (and significant) quantity of cells initially, and this point is not always possible especially by working with certain

\section{Biomed Central}


primary cultured tumor cells. Thus, and in spite of the fact that the method here exposed is an indirect method of quantification of DNA methylation, it provides the possibility to estimate the DNA methylation status from a weak quantity of biologic materiel such as stem cells or primary cultured tumor cells for examples.

\section{Results}

The technology that we present here is based on the detection of protein-protein interactions via the adaptation of the proximity ligation in situ technology to the context of DNA methylation [13]. Based on the demonstration that the interaction between Dnmt1 and PCNA plays a crucial role into the DNA methylation inheritance, we decided to monitor and quantify the Dnmt1/ PCNA interaction by proximity ligation in situ assay (P-LISA) in cells $[14,15]$. As illustrated by the Figure 1A, the principle of this assay is based on the staining of Dnmt1 and PCNA proteins by two antibodies, which are next revealed by secondary antibodies conjugated with oligonucleotides. In presence of hybridization solution and ligase, the two oligonucleotides form with PLA a circle in case of close proximity of proteins i.e. Dnmt1 and PCNA, here. Then, polymerase and nucleotides participate to the formation of the rolling circle amplification, which are visualized in red fluorescence. Pictures were realized by using microscopy (Axiovert $200 \mathrm{M}$ Zeiss, Le Pecq, France) with ApoTome module. To take in consideration the possible presence of chromatic aberration, we have performed calibration with specific balls of calibration akin the P-LISA signal (Figure 1B). The signal being inferior to the axial resolution and in order to reduce the diffraction, we next decided to decovolve the image by using the Huygens Essential software (Figure 1C). Next, the Huygens's decovovling is used with the "nipkow disk" method. The decovolving makes it possible to solve a signal of low diameter and to increase the quality of the 3D reconstitution. The $3 \mathrm{D}$ reconstitution is obtained by using Amira.4.1.1 program.

By using ApoTome technology, we can visualize the interactions of endogenous proteins Dnmt1 and PCNA (Figure 1D). Moreover, the use of this method validated the idea that the Dnmt1/PCNA interactions occur in nucleus and permitted to quantify the number of interaction per nucleus.

To validate the possibility to use the Dnmt1/PCNA P-LISA to evaluate the degree of DNA hypomethylation in cells, we compared whether the number of Dnmt1/ PCNA interactions was correlated with the values of 5 $\mathrm{mC}$ number quantification (ELISA method) in nontumor and tumor breast cell lines. P-LISA and ELISA experiments realized from non-tumor and tumor breast cell lines revealed that that tumor cells (MDA-MD-231 and Cal-51) harbored less Dnmt1/PCNA interactions

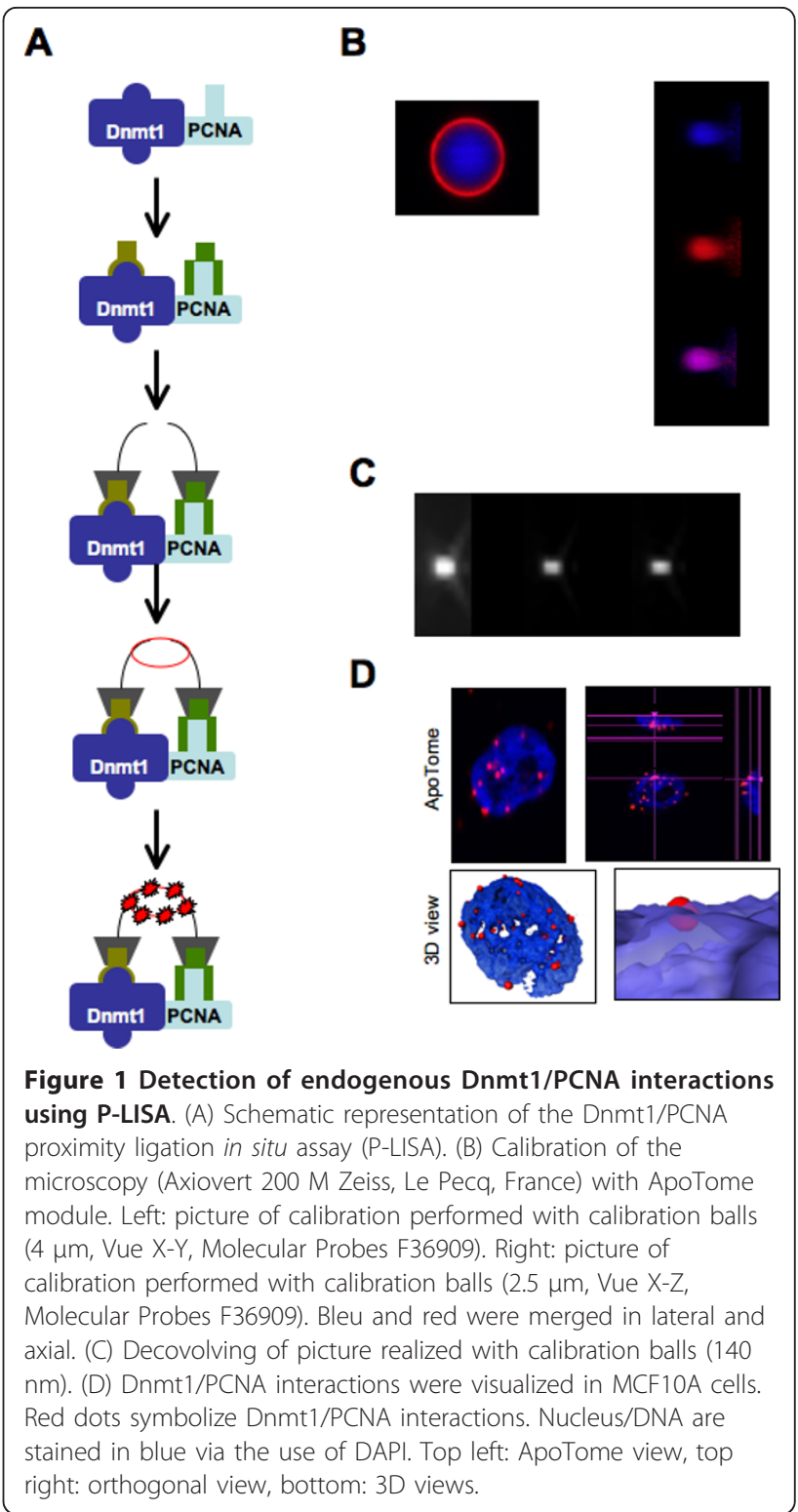

and less 5-methycytosine $(5 \mathrm{mC})$ than non-tumor cells (MCF10A) (Figures 2A and 2B). In others terms, these results suggest that the DNA is less methylated in tumor cells than in non-tumor cells since tumors cells harbored less Dnmt1/PCNA interactions. By plotting the value of $5 \mathrm{mC}$ and the number of Dnmt1/PCNA interactions per nucleus against each other, it appears that the level of $5 \mathrm{mC}$ was correlated with the number of Dnmt1/PCNA interactions per nucleus (Figure 2C).

To test the idea that the Dnmt1/PCNA interaction can be used to estimate the level of global DNA methylation, we analyzed the effect of DNA hypomethylating agents/ strategies on the Dnmt1/PCNA interactions. Thus, we firstly monitored the $5 \mathrm{mC}$ number and the Dnmt1/ PCNA interactions in cells harboring an increasing 


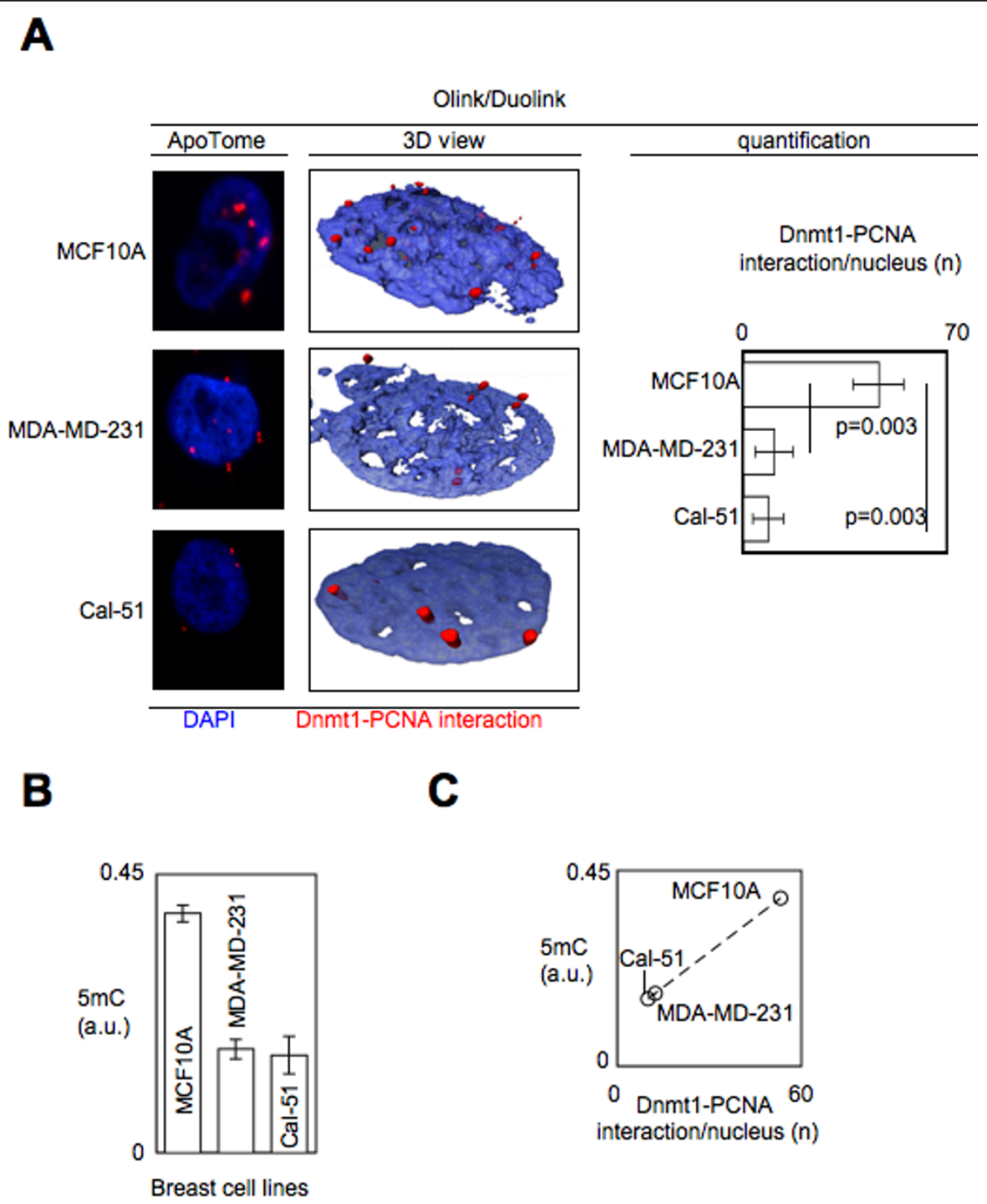

Figure 2 Decrease of Dnmt1/PCNA interaction is associated with the decrease of the DNA methylation. (A) Dnmt1/PCNA P-LISA in nontumor cells (MCF10A) and in tumor cells (MDA-MD-231 and Cal-51). Red dots symbolize Dnmt1/PCNA interactions. Nucleus/DNA are stained in blue via the use of DAPI. The number of Dnmt1/PCNA interactions is calculated from the analysis of 100 nuclei. (B) Evaluation of the degree of DNA methylation in cells by using $5 \mathrm{mC}$-ELISA. (C) Correlation between the $5 \mathrm{mC}$ (5-methylcyctosine) number and the number of Dnmt1/PCNA interactions.

deficiency of Dnmt1 expression. For this purpose, we used U251 cells and siRNA directed against Dnmt1. As illustrated by the Figure 3A, ELISA monitoring the Dnmt1 expression indicated that the Dnmt1 expression decreased when the quantity of siRNA treating the cells increased. ELISA assessing the $5 \mathrm{mC}$ and P-LISA measuring the Dnmt1/PCNA interactions revealed that the siRNAmediated decrease of Dnmt1 expression was correlated with the decrease of $5 \mathrm{mC}$ and with the decrease of Dnmt1/PCNA interactions (Figure 3A). In addition, a Pearson's correlation test also showed a significant correlation between the number of Dnmt1/PCNA interactions and the number of $5 \mathrm{mC}(\mathrm{r}=0.983, \mathrm{p}=0.0004)$ (Figure $3 \mathrm{~B})$. Secondly, we analyzed the effect of the 5-aza-2-deoxycytidine treatment on the number of Dnmt1/PCNA interactions and on the DNA methylation status in U251 cells. In absence of toxic effect of our 5aza treatment, we observed, in parallel, significant decreases of the number of Dnmt1/PCNA interactions, of the DNA methylation status and of the level of the Dnmt1 expression (Figure 4). Through these two last experiments, we noted that the decrease of the number of Dnmt1/PCNA interactions is associated with the decrease of $5 \mathrm{mC}$ under a context of decrease of Dnmt1 expression. 

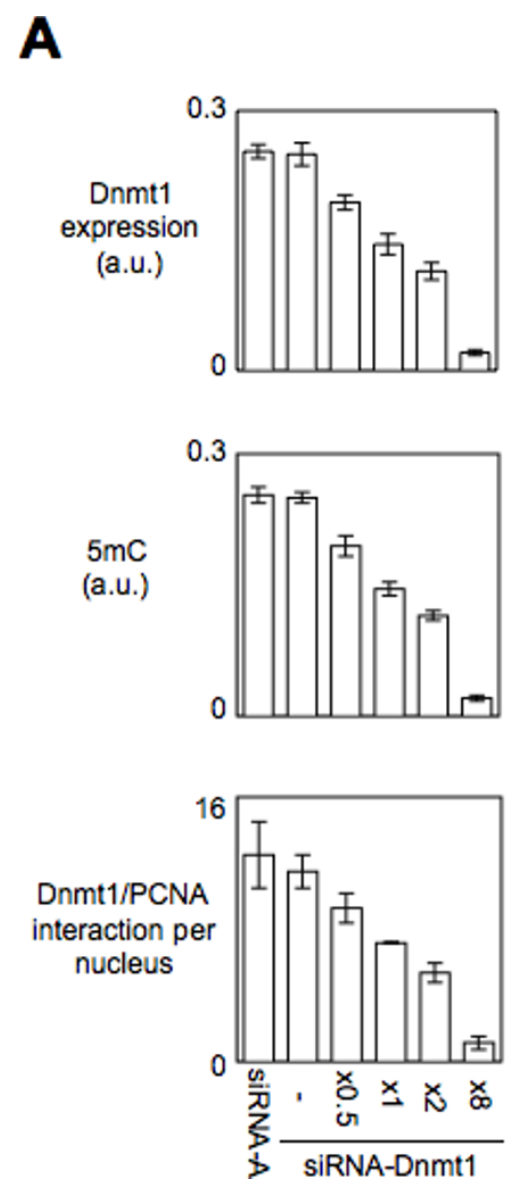

Figure 3 siRNA-mediated down-expression of Dnmt1 promoted the decrease of Dnmt1/PCNA interactions and the decrease of $5 \mathrm{mC}$ in U251 cells. (A) Impact of the siRNA-Dnmt1 treatments on the expression of Dnmt1 (ELISA method according to our previous report [17]), on the $5 \mathrm{mC}$ (ELISA method) and on the number of Dnmt1/PCNA interactions (P-LISA method). siRNA-Dnmt1 (sc-35204, Tebu-Bio, France) (B) Correlation between the $5 \mathrm{mC}$ (5-methylcyctosine) number and the number of Dnmt1/PCNA interactions.

After the analyses of the conditions reducing the Dnmt1/PCNA interactions and/or the degree of DNA methylation, we now considered the condition increasing the Dnmt1/PCNA interactions and/or the degree of DNA methylation. Physiologically, the degree of DNA methylation increases between the G1 and S phases of the cell cycle since, after the DNA replication, the neosynthesized strand of DNA is methylated according to the pattern of methylation of the parental strand in order to promote the DNA methylation inheritance process. Thus, we next analyzed the evolution of the degree of DNA methylation and of the number of Dnmt1/ PCNA interaction when cells were in G1/G0 and S phases of the cell cycle. For this purpose, U251 cells were blocked in G0/G1 and S phases by using serum deprivation and thymidine treatments after a first synchronization by serum deprivation (Figure 5A). P-LISA and $5 \mathrm{mC}$ ELISA were realized in parallel to monitor the number of Dnmt1/PCNA interactions and the degree of DNA methylation. As illustrated by the
B

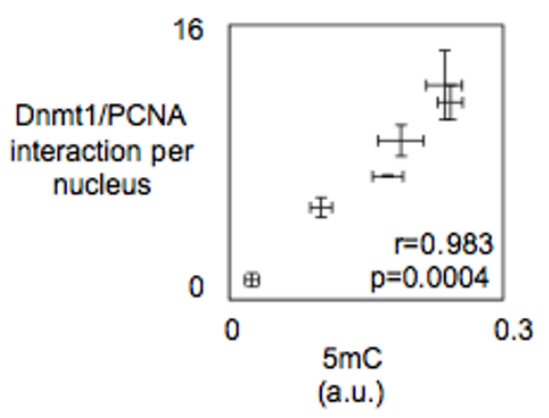

Figures $5 \mathrm{~B}$ and $5 \mathrm{C}$, we observed that the significant increase of Dnmt1/PCNA interactions in S phase is associated with the significant increase of the $5 \mathrm{mC}$ number $(\mathrm{p}=0.0013$ and $\mathrm{p}=0.0188)$.

The degree of DNA methylation can also increase when cells are performing de novo methylation by Dnmt3. To aim this situation, we have used the U87pORF-Dnmt3a cells since we have already used these cells to promote the methylation of the caspase- 8 gene [16]. Under this condition, we observed that the global level of DNA methylation and the number of Dnmt1/ PCNA interactions unchanged 2-days after the cells transfection $(\mathrm{p}=0.7262$ and $\mathrm{p}=0.4918)$ (despite the fact that the methylation level of caspase 8 gene was already increased at this point $(\mathrm{p}<0.0001))$, while we observed an increase of the global level of DNA methylation and of the number of Dnmt1/PCNA interactions 4-days after the cells transfection $(\mathrm{p}=0.0292$ and $\mathrm{p}=$ 0.0142) (Figure 5D). Interestingly, these data suggest that the number of Dnmt1/PCNA interactions increases 


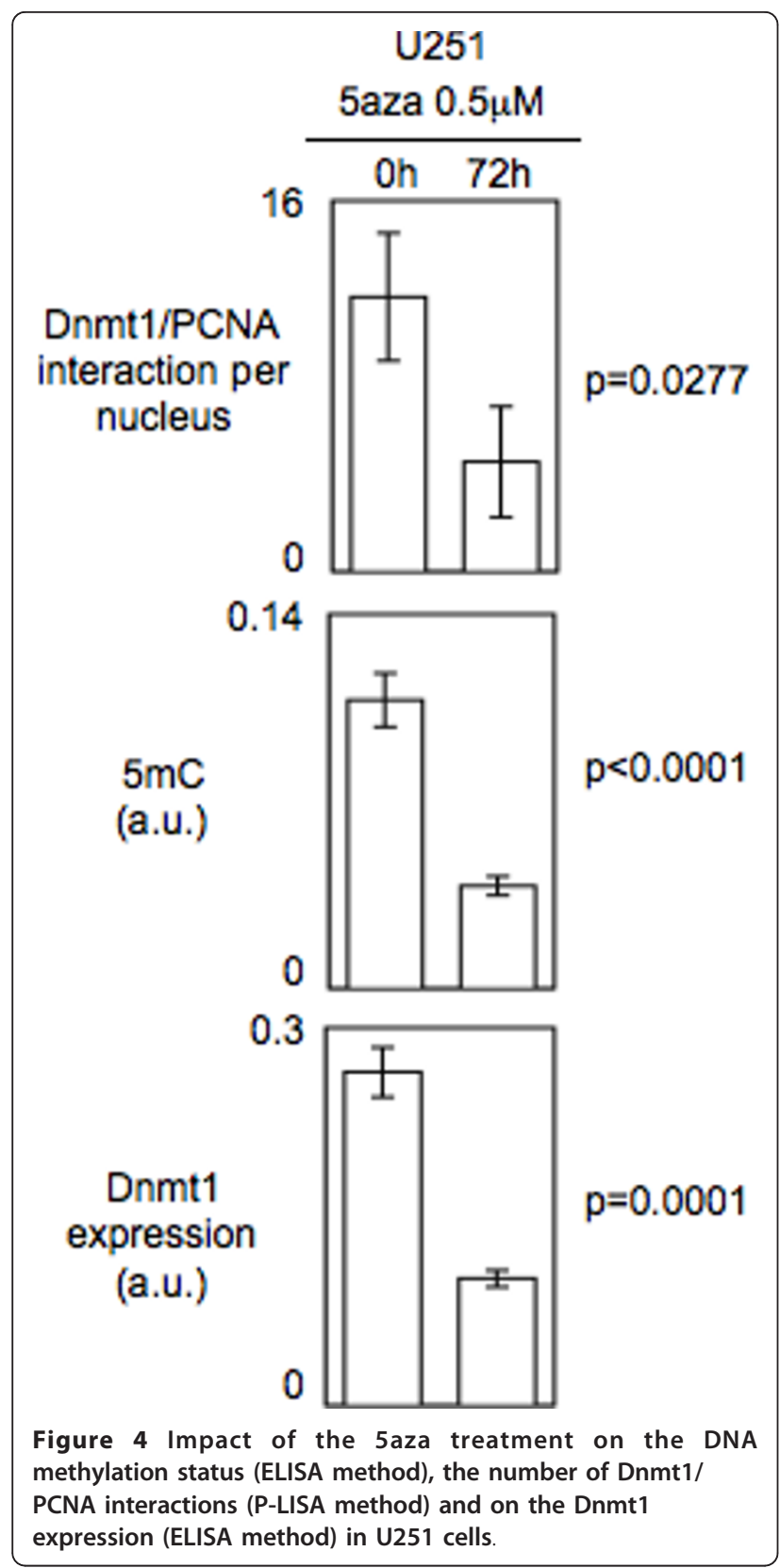

in response to the Dnmt3a-induced increase of the $5 \mathrm{mC}$ number. However, the Dnmt1/PCNA interactions monitoring was not representative of the methylation degree of the caspase- 8 gene. Thus, these data suggest that the Dnmt1/PCNA interactions monitoring is not recommended to analyze the methylation of level of specific gene.

\section{Discussion}

In terms of methodology, all our data argue that the Dnmt1/PCNA Proximity-Ligation In Situ Assay presented here should enable to reflect the degree of DNA methylation in cells. Indeed, that its is following a DNA hypomathylation strategy (inhibition of the Dnmt1 expression or treatment (5aza) or by comparing non tumor cells with tumor cells, the number of Dnmt1/ PCNA interactions echoes the degree of DNA methylation. In addition this method being performed from fixated cells, it is adapted for investigation realized from weak quantity of biologic materiel (Stem cells, biopsies samples...) on contrary to the majority of technologies aiming at analyzing the degree of DNA methylation (and mentioned into the introduction section). One other advantage of this method is into the fact that it does no require to transform the cells with plasmid or to extract DNA or nuclear samples in order to perform $5 \mathrm{mC}$-ELISA, to measure of mMTase, for example. In addition, our data indicate that it is not necessary to take into consideration the expression level of Dnmt1 and/or PCNA since none correlation between the Dnmt1 level expression and the $5 \mathrm{mC}$ number was observed in a large number of glioma and 2) since the Dnmt1/PCNA interactions can be inhibited by other events that the level expression of these proteins (such as the phosphorylation of Dnmt1, the presence of peptide/protein imitating the action of the UP peptide $[17,18]$.

Supported by these points, we thus envision a wide range of applications for the Dnmt1/PCNA P-LISA in basic research and into the development of DNA hypomethylation strategies based or not on the inhibition of the complexes including the Dnmt1/PCNA interactions such as the one including the Dnmt1/PCNA/UHRF1 which is considered as the main player of the DNA methylation inheritance.

In terms of biologic results, our data show that the breast cancer cell lines (MDA-MD-231 and Cal-51) harbored less Dnmt1/PCNA interactions and less 5-methycytosine $(5 \mathrm{mC})$ than non-tumor breast cells (MCF10A). Thus, breast cancer appears as the second, after glioma, in which we observed that the DNA hypomethylation characterizing the tumor cells is correlated with the decrease of Dnmt1/PCNA interactions $[17,18]$. Besides, the fact that DNA of breast cancer cells is hypomethylation in comparison with DNA of breast cells is a welldocumented point by the literature [19-21]. The fact that the degree of DNA methylation is correlated with the level of Dnmt1/PCNA interactions makes sense with the fact that the Dnmt1 and PCNA, are two crucial actors, with UHRF1, of the main multiprotein complex, promoting the DNA methylation inheritance in mammalian cells $[15,22]$. In addition, our data indicate that the Dnmt1/PCNA interactions are increased, such as the DNA methylation level, during the $S$ phase in comparison with the number of Dnmt1/PCNA interactions and the DNA methylation level characterizing the G0/ 


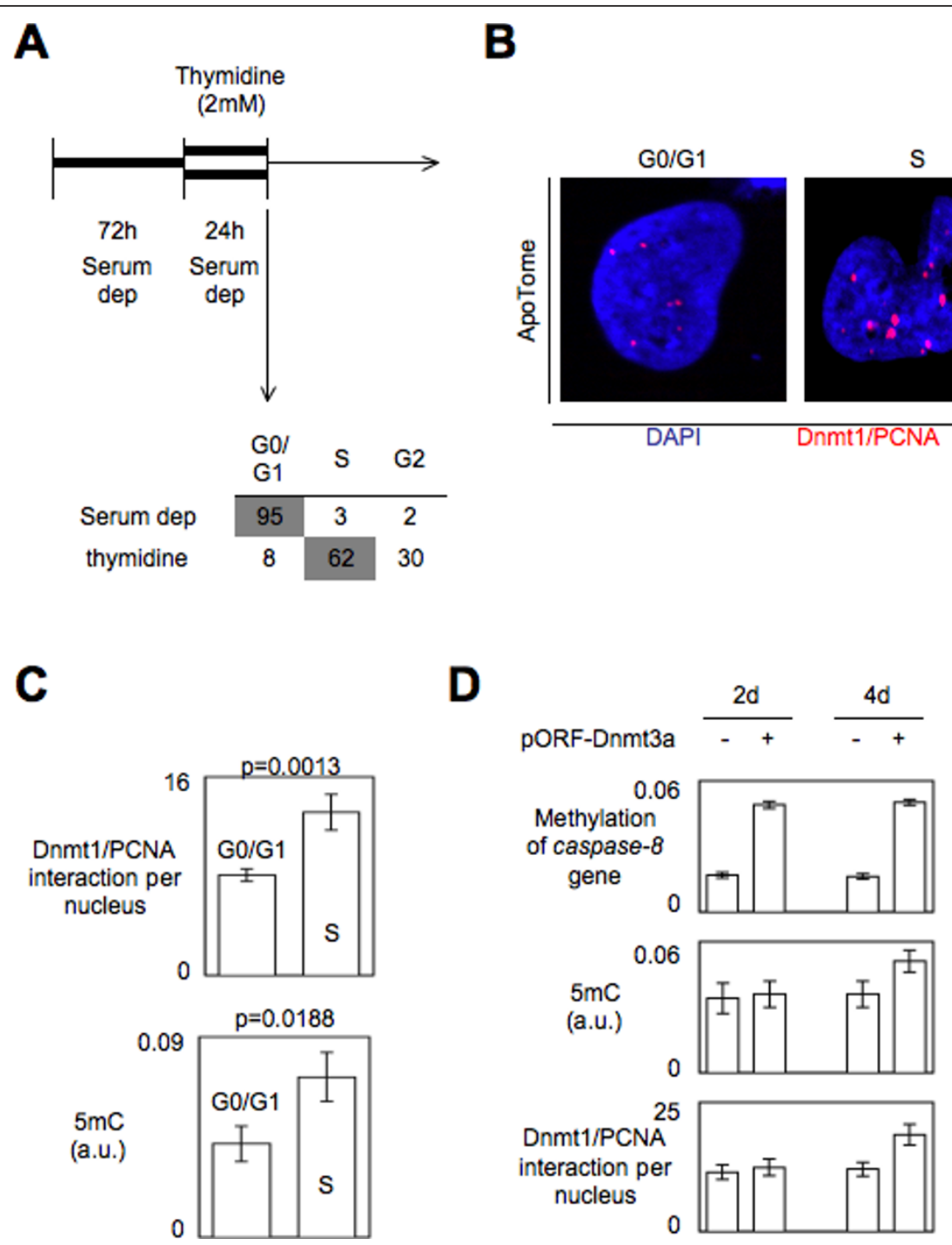

Figure $5 \mathrm{Impact}$ of conditions increasing the level of DNA methylation on the number of Dnmt1/PCNA interactions. (A) Characterization cell cycle of arrest. U251 cells were treated by serum deprivation (72 h) or by thymidine (2 mM, 24 h), previous to perform cell cycle analysis by using the NucleoCounter NC-3000TM Kit, Chemometec, France). (B) Dnmt1/PCNA P-LISA in U251 cells blocked in G0/G1 or S phases of the cell cycle. Red dots symbolize Dnmt1/PCNA interactions. Nucleus/DNA are stained in blue via the use of DAPI. (C) Analysis of the number of Dnmt1/ PCNA interactions (P-LISA) and the $5 \mathrm{mC}$ number (ELISA). The number of Dnmt1/PCNA interactions is calculated from the analysis of 100 nuclei. (D) Impact of the Dnmt3a overexpression in U87 cells on the level of methylation of the capase-8 gene (MeDIP), on DNA (5 mC ELISA) and on the number of Dnmt1/PCNA interactions. The number of Dnmt1/PCNA interactions is calculated from the analysis of 100 nuclei. U87-pORFDnmt3a and the U87-pORF (transfection control (-)) were obtained as previously described [16].

G1 phase. Thus, the use of the Dnmt1/PCNA P-LISA confirms a dogma of epigenetic reporting that the DNA methylation inheritance catalyzed by the complex including the Dnmt1/PCNA interactions is a process mainly realized during the $S$ phase [15,22]. In addition, the use of P-LISA could be interesting to monitor the interactions existing between the Dnmt1 protein (the main enzyme catalyzing the DNA methylation inheritance) and different of its interaction partner during the cell cycle. Besides, these investigations are an ongoing subject in our lab and take place into the debate aiming to characterize the dynamism and the kinetic of the DNA methylation inheritance catalyzed by the Dnmt1 during the cell cycle. Our data also indicate that the monitoring of the Dnmt1/PCNA interactions was not representative of the increase of the methylation degree of the caspase- 8 gene following the Dnmt3a overexpression, but that at middle term (4-days) the number of Dnmt1/PCNA interactions reflected the Dnmt3ainduced increase of $5 \mathrm{mC}$. Thus, our data suggest that 
the monitoring of the Dnmt1/PCNA interactions is not a method adapted to analyze the degree of methylation of a specific gene but is adapted to monitor the degree of DNA methylation. In addition, the increase of Dnmt1/PCNA interactions in Dnmt3a-induced upmethylated cells was not associated with the Dnmt1 or PCNA overexpression (data not shown). Thus, these data suggest that, after a step of de novo methylation catalyzed by the Dnmt3 in "mother cells", "daughter cells" could adapt the number of Dnmt1/PCNA interactions to maintain the DNA methylation pattern realized by the Dnmt3 in "mother cells". Thus, there is an adaptation of the cells according its requirements of DNA methylation inheritance and not according the relative quantity of Dnmt1 and PCNA. This point impacts the methodology of the use of the Dnmt1/PCNA P-LISA for monitoring the global DNA methylation in cells since this suggests that it is not necessary to normalize the counting of P-LISA to the protein level of Dnmt1 and PCNA.

\section{Conclusion}

The detection of the Dnmt1/PCNA interactions via the proximity ligation in situ assay to the estimate the degree of DNA methylation in cells appears as an attractive method since 1) it is applicable to a weak quantity of cells, 2) it limits the number of protocol step (no DNA extract, no transfection,...), 3) it reflects the fact that cancer cells are hypomethylated in comparison with no tumor cells, and 4) it echoes the effect of DNA hypomethylating agents/strategies.

\section{Methods}

\section{Proximity ligation in situ assay}

Cells were cultivated for $24 \mathrm{~h}$ on cover slip. Cells were then fixed with 4\% paraformaldehyde in PBS pH7.4 for $15 \mathrm{~min}$ at room temperature. Permeabilization is performed with PBS containing $0.5 \%$ Triton $100 \times 4$ for 20 min at room temperature. Blocking, staining, hybridization, ligation, amplification and detection steps were realized according to manufacturer's instructions (Olink Bioscience). During these steps, all incubations were performed in a humidity chamber. Amplification and detection steps were performed in dark room. Fluorescence was visualized by using the Axiovert $200 \mathrm{M}$ microscopy system (Zeiss, Le Pecq, France) with ApoTome module (X63 and numerial aperture 1.4). Preparations were mounted by using ProLong ${ }^{\circledR}$ Gold antifade reagent with DAPI (InVitrogen, France). Pictures acquisition was realized in structured illumination microscopy [23]. Thus, the lateral resolution $(\mathrm{rl})$ is, according to the Rayleigt criteria: $\mathrm{rl}=0.61 \lambda / \mathrm{NA}(\lambda$ : wavelength; NA: numerical aperture of the objective), and the axial resolution, in ApoTome, is defined by the full-width half maximum (FWHMz)

$$
\operatorname{FWHM}(z)=\frac{3.83}{16 \pi} \cdot \frac{\lambda \times 10^{-3}}{n \cdot \sin ^{2}(\alpha / 2) \bar{v}(1-\bar{v} / 2)}
$$

In this equation, $\lambda$ is the emission wavelength, $\mathrm{n}$ is the index of medium refraction, $v$ is the frequency and $\alpha$ is the angle of opening of the objective as previously described [24]. After decovolving (3.5 Huygens Essential software (SVI)), 3D view was obtained by using Amira.4.1.1 program. Finally, the image were analyzed by using the freeware "BlobFinder available for download from http://www.cb.uu.se/ amin/BlobFinder. Thus, we obtained either number of signals per nuclei since nuclei can be automatically identified. In other terms, the use of this program participates to the normalization, standardization, reproducibility and to the definition of the cut off signal to accept/quantify or not a dot.

\section{5methylcytosine ELISA (5 mC-ELISA) and Methylated DNA ImmunoPrcipitation experiments (MeDIP)}

DNA was extracted by using the QiaAmp DNA mini Kit (Qiagen, France), and $5 \mathrm{mC}$-ELISA was performed by using the Methylamp Global DNA Methylation Quantification kit (Epigentek-Euromedex, France). DNA ImmunoPrecipitation (MeDIP) were performed by using MethylCollector ${ }^{\mathrm{TM}}$ kit according to the manufacturer's instructions (Active Motif, France). qPCR were realized to analyze the level of DNA methylation of a considered gene with specific primers (s: CAGGAGGTGGAGG TTGC andas: GAGCCCTAGACCCTCCC) and according our previous report [17].

\section{Genes invalidation experiments}

Dnmt1 gene was invalidated by using siRNA approach (sc35204, Tebu-Bio France) according to manufacturer's instructions. siRNA-A was used as control (sc37007, Tebu-Bio France). Classical siRNA treatment (referred as $\mathrm{x} 1$ ) was performed by using 60 pmols of considered siRNA.

\section{Acknowledgements}

This work was supported by a grant from the "Association pour la Recherche contre le Cancer" (ARC\#3907 and ARC\#1020). We thank to Philippe Juin for giving the breast cell lines.

\section{Author details}

${ }^{1}$ Centre de Recherche en Cancérologie Nantes-Angers, INSERM, U892, Equipe Apoptose et Progression Tumorale, Equipe labellisée Ligue Nationale Contre le Cancer. 8 quai moncousu, BP7021, 44007 Nantes, France. ${ }^{2}$ Université de Nantes, Faculté de Médecine, Département de Recherche en Cancérologie, IFR26, F-4400, Nantes, France. ${ }^{3}$ PICell, Plateau technique d'imagerie cellulaire - IFR26 - Centre de Recherche en Cancérologie Nantes-Angers, INSERM, U892. F-4400, Nantes, France. 


\section{Authors' contributions}

$\mathrm{EH}, \mathrm{PH}$ and PFC carried out the experimental study. FMV and PFC designed the experiments. All authors participated in the analysis of the results, contributed in the preparation of the manuscript and approved the final manuscript.

Received: 29 October 2010 Accepted: 6 April 2011 Published: 6 April 2011

\section{References}

1. Robertson K, Wolffe A: DNA methylation in health and disease. Nat Rev Genet 2000, 1(1):11-19.

2. Bird A: DNA methylation patterns and epigenetic memory. Genes Dev 2002, 16(1):6-21.

3. Esteller M: Epigenetics in cancer. N Engl J Med 2008, 358(11):1148-1159

4. Gaudet F, Hodgson JG, Eden A, Jackson-Grusby L, Dausman J, Gray JW, Leonhardt $\mathrm{H}$, Jaenisch R: Induction of tumors in mice by genomic hypomethylation. Science 2003, 300(5618):489-492.

5. Eden A, Gaudet F, Waghmare A, Jaenisch R: Chromosomal instability and tumors promoted by DNA hypomethylation. Science 2003, 300(5618):455.

6. Hervouet E, Debien E, Charbord J, Menanteau J, Vallette FM, Cartron PF: Folate supplementation: a tool to limit the aggressiveness of gliomas via the re-methylation of DNA repeat element and genes governing apoptosis and proliferation. Clinical Cancer Research 2009, 15(10):3519-3529.

7. Beier V, Mund C, Hoheisel J: Monitoring methylation changes in cancer. Adv Biochem Eng Biotechnol 2007, 104:1-11.

8. Kuo K, McCune R, Gehrke C, Midgett R, Ehrlich M: Quantitative reversedphase high performance liquid chromatographic determination of major and modified deoxyribonucleosides in DNA. Nucleic Acids Res 1980, 8(20):4763-4776.

9. Stach D, Schmitz O, Stilgenbauer S, Benner A, Döhner H, Wiessler M, Lyko F: Capillary electrophoretic analysis of genomic DNA methylation levels. Nucleic Acids Res 2003, 31(2):E2

10. Xiong Z, Laird PW: COBRA: a sensitive and quantitative DNA methylation assay. Nucleic Acids Res 1997, 25(12):2532-2534.

11. King C, Scott-Horton T: Pyrosequencing: a simple method for accurate genotyping. J Vis Exp 2008, 11, (pii: 630).

12. Schermelleh L, Spada F, Easwaran H, Zolghadr K, Margot J, Cardoso M, Leonhardt H: Trapped in action: direct visualization of DNA methyltransferase activity in living cells. Nat Methods 2005, 2(10):751-756.

13. Söderberg $O$, Gullberg $M$, Jarvius $M$, Ridderstråle K, Leuchowius K, Jarvius J, Wester K, Hydbring P, Bahram F, Larsson L, et al: Direct observation of individual endogenous protein complexes in situ by proximity ligation. Nat Methods 2006, 3:12.

14. Chuang LS, Ian HI, Koh TW, Ng HH, Xu G, Li BF: Human DNA-(cytosine-5) methyltransferase-PCNA complex as a target for p21WAF1. Science 1997, 277(5334):1996-2000.

15. Sharif J, Muto M, Takebayashi S, Suetake I, Iwamatsu A, Endo T, Shinga J, Mizutani-Koseki Y, Toyoda T, Okamura K, et al: The SRA protein Np95 mediates epigenetic inheritance by recruiting Dnmt1 to methylated DNA. Nature 2007, 450(7171):908-912.

16. Hervouet $E$, Vallette F, Cartron P: Impact of the DNA methyltransferases expression on the methylation status of apoptosis-associated genes in glioblastoma multiforme. Cell Death and Disease 2010, 1(e8).

17. Hervouet E, Debien E, Cheray M, Hulin P, Loussouarn D, Martin SA, Vallette FM, Cartron PF: Disruption of Dnmt1/PCNA/UHRF1 interactions promotes tumorigenesis by inducing genome and gene-specific hypomethylations and chromosomal instability. PLOS ONE 2010, 5(6): e11333.

18. Hervouet E, Lalier L, Debien E, Cheray M, Geairon A, Rogniaux H, FM V, Cartron PF: Tumor induction by disruption of the Dnmt1, PCNA and UHRF1 interactions. Nature Precedings 2008 [http://hdl.handle.net/10101/ npre.2008.2509.1].

19. Jackson K, Yu M, Arakawa K, Fiala E, Youn B, Fiegl H, Müller-Holzner E, Widschwendter M, Ehrlich M: DNA hypomethylation is prevalent even in low-grade breast cancers. Cancer Biol Ther 2004, 3(12):1225-1251.

20. Gama-Sosa M, Slagel V, Trewyn R, Oxenhandler R, Kuo K, Gehrke C, Ehrlich M: The 5-methylcytosine content of DNA from human tumors. Nucleic Acids Res 1983, 11(19):6883-6894.
21. Szyf M, Pakneshan P, Rabbani S: DNA methylation and breast cancer. Biochem Pharmacol 2004, 68(6):1187-1197.

22. Bostick M, Kim J, Estève P, Clark A, Pradhan S, Jacobsen S: UHRF1 plays a role in maintaining DNA methylation in mammalian cells. Science 2007, 27(15):2187-2197.

23. Schaefer L, Schuster D, Schaffer J: Structured illumination microscopy: artefact analysis and reduction utilizing a parameter optimization approach. J Microsc 2004, 216(Pt 2):165-174.

24. Neil M, Juskaitis R, Wilson T: Method of obtaining optical sectioning by using structured light in a conventional microscope. Opt Lett 1997, 22(24):1905-1907.

doi:10.1186/1472-6750-11-31

Cite this article as: Hervouet et al:: Proximity ligation in situ assay for monitoring the global DNA methylation in cells. BMC Biotechnology 2011 $11: 31$.

\section{Submit your next manuscript to BioMed Central and take full advantage of:}

- Convenient online submission

- Thorough peer review

- No space constraints or color figure charges

- Immediate publication on acceptance

- Inclusion in PubMed, CAS, Scopus and Google Scholar

- Research which is freely available for redistribution

Submit your manuscript at www.biomedcentral.com/submit
C) Biomed Central 